\title{
Recommendations for preventing fracture in long-term care
}

\author{
Alexandra Papaioannou MD MSc, Nancy Santesso RD PhD, Suzanne N. Morin MD MSc, Sidney Feldman MD, \\ Jonathan D. Adachi MD, Richard Crilly BSc MD, Lora M. Giangregorio PhD, Susan Jaglal PhD, \\ Robert G. Josse MBBS, Sharon Kaasalainen PhD, Paul Katz MD, Andrea Moser MD MSc, Laura Pickard MA, \\ Hope Weiler RD PhD, Susan Whiting PhD, Carly J. Skidmore MSc, Angela M. Cheung MD PhD; \\ for the Scientific Advisory Council of Osteoporosis Canada
}

CMAJ Podcasts: author interview at https://soundcloud.com/cmajpodcasts/141331-guide

$\mathrm{T}$ he 2010 clinical practice guideline for the diagnosis and management of osteoporosis in Canada ${ }^{1}$ focused on the care of adults living in the community. However, the fracture rate for adults living in long-term care (residents) is two to four times that of adults of similar age living in the community, and one-third of older adults who experience hip fracture are residents in long-term care. ${ }^{2}$ Hip fracture is one of the most serious consequences of osteoporosis and also one of the leading causes of admission to hospital. ${ }^{3}$ When residents return to long-term care after a hospital stay, they need additional hours of specialized care. ${ }^{4,5}$ In addition, fracture pain and delirium frequently associated with analgesia are distressing for residents and their families. Vertebral fractures are also a concern for residents, and the reported prevalence is up to $30 \%$ (for at least one moderate to severe fracture). ${ }^{6}$ Multiple vertebral fractures can be a substantial cause of pain, anxiety, depression, reduced pulmonary function ${ }^{7}$ and agitation.

Frail older adults at high risk of fracture in long-term care face other challenges. More than $40 \%$ have dementia, ${ }^{8}$ a similar percentage experience swallowing difficulties, ${ }^{9,10}$ and over $20 \%$ may have renal insufficiency. ${ }^{11,12}$

It may be difficult to identify residents at high risk of fracture, as the current fracture risk assessment tools (the Canadian Association of Radiologists and Osteoporosis Canada tool ${ }^{13}$ [CAROC; www.osteoporosis.ca/multimedia/pdf/ CAROC.pdf] and the Canadian WHO Fracture Risk Assessment Tool [FRAX; www.shef.ac.uk/ FRAX/]) provide 10-year fracture risk and have not been validated in long-term care, where over $20 \%$ of residents may die within one year of admission. ${ }^{14,15}$ Most research regarding risk assessment and pharmacologic therapies has not included those with multiple comorbidities. ${ }^{16,17}$

\section{Scope}

This document provides guidance regarding strategies for the prevention of fractures directed toward interprofessional teams caring for frail older adults in long-term care.

\section{Methods}

This guideline, which has been endorsed by Osteoporosis Canada, was developed using the Grading of Recommendations Assessment, Development and Evaluation (GRADE) approach ${ }^{18,19}$ (www. gradeworkinggroup.org), in a process led by a GRADE methodologist (N.S.). The guideline panel comprised the authors, other multidisciplinary health care providers and researchers, and representatives from resident and family councils (see Appendix 1, available at www.cmaj.ca/lookup/ suppl/doi:10.1503/cmaj.141331/-/DC1). The panel was first surveyed to prioritize questions and important outcomes. In addition to fractures (hip, vertebral and nonvertebral), the group as a whole identified pain, quality of life, loss of activities of daily living and mobility, death and adverse events requiring medical attention as important outcomes. Family members of residents ranked prevention of pain and maintenance of mobility as most important.

We conducted systematic searches of the literature for published network meta-analyses, system-

\section{KEY POINTS}

- In older adults living in long-term care (residents), fractures cause pain, agitation, immobility and transfers to hospital.

- Residents identified as being at high risk of fracture include those with prior fracture of the hip or spine, those with more than one prior fracture and those with one prior fracture and recent use of glucocorticoids.

- Recommendations for preventing fracture in long-term care were developed using the GRADE (Grading of Recommendations Assessment, Development and Evaluation) approach, with consideration of the quality of the available evidence, the balance between benefits and harms, the preferences of residents and their care providers, and the resources required to implement the recommendations.

- Strategies to prevent fractures, including vitamin D and calcium supplementation, use of hip protectors, exercise, multifactorial interventions to prevent falls and pharmacologic therapies, should be tailored to each resident's level of fracture risk, mobility, life expectancy, renal function and ability to swallow. 
atic reviews, randomized controlled trials and nonrandomized studies up to June 2013. Details of the synthesis of the evidence, preparation of evidence profiles and evidence-to-decision tables for five key strategies to prevent fracture (vitamin D and calcium intake, osteoporosis medications, hip protectors, exercise and multifactorial interventions) are presented in Appendix 1. Briefly, evidence for relative risks and differences among interventions were converted to absolute effects with $95 \%$ confidence intervals (CIs) and were presented in evidence profiles. When data regarding fractures in long-term care were not available, we used data for adults 75 years and older. The overall annual rate of hip, vertebral and other fractures in longterm care residents was $2 \%, 2,20-22$ for those at high risk, the annual rate of vertebral fracture was $20 \%,{ }^{23}$ and annual rates were estimated to be $6 \%$ for hip fracture and $6 \%$ for all other fractures.

We assessed the quality of the evidence as high, moderate, low or very low according to the GRADE criteria $^{18}$ (Table 1). The evidence-todecision tables presented to the panel for consideration included a summary of the evidence for benefits and harms, the quality of the evidence, relevant values and preferences of residents and their families, resource use and feasibility. Recommendations were assessed as "strong" or "conditional" (Table 2). Strong recommendations are worded as "we recommend" and conditional recommendations as "we suggest."

\section{Recommendations}

We developed recommendations for interventions to prevent fracture for two groups: older residents in long-term care who are at high risk of fracture and older residents who are not at high risk of fracture.

Until a method for defining those at high risk of fracture in long-term care has been validated, we propose an adaptation of the definition presented in the 2010 Osteoporosis Canada guideline,${ }^{1}$ which relies heavily on fracture history (Box 1). If a resident has been identified as having a high risk of fracture and has received osteoporosis treatments before admission to long-term care, that classification may continue to apply at admission.

Screening for vertebral fractures as described in the 2010 guideline $^{1}$ is recommended. If a lateral view is included when chest radiography is ordered, a request can also be made to screen for vertebral fractures.

\section{Calcium and vitamin D}

\section{Calcium}

For all residents, we recommend dietary interventions to meet the recommended dietary allowance for calcium (strong recommendation; moderate-quality evidence).

This recommendation places a high value on reductions in fractures, mortality and falls and a

Table 1: Quality of evidence: confidence in effect ${ }^{18}$

Rating of evidence quality

High

Moderate

Low

Very low
Definition

We are very confident that the true effect lies close to that of the estimate of the effect.

We are moderately confident in the effect estimate. The true effect is likely to be close to the estimate of the effect, but there is a possibility that it is substantially different.

Our confidence in the effect estimate is limited. The true effect may be substantially different from the estimate of the effect.

We have very little confidence in the effect estimate. The true effect is likely to be substantially different from the estimate of effect.

Table 2: Interpretation of strong and conditional recommendations for fracture prevention ${ }^{19}$

\begin{tabular}{|lll|}
\hline & \multicolumn{1}{c|}{\begin{tabular}{c} 
Type of recommendation; implication for target group \\
\cline { 2 - 4 } Target group
\end{tabular}} & $\begin{array}{c}\text { Strong recommendation } \\
\text { ("We recommend ...") }\end{array}$ \\
\hline Patients & $\begin{array}{l}\text { Most individuals in this situation would want the } \\
\text { recommended course of action, and only a small } \\
\text { proportion would not. }\end{array}$ & $\begin{array}{l}\text { The majority of individuals in this situation would } \\
\text { want the suggested course of action, but many would } \\
\text { not. }\end{array}$ \\
\hline Clinicians & Most individuals should receive the intervention. & $\begin{array}{l}\text { Clinicians recognize that different choices will be } \\
\text { appropriate for each individual patient and that } \\
\text { clinicians must help each individual arrive at a } \\
\text { management decision consistent with his or her } \\
\text { values and preferences. }\end{array}$ \\
\hline
\end{tabular}


lower value on the resources in long-term care that are required to implement interventions to ensure adequate dietary intake of calcium. This recommendation is based on evidence evaluating the effects of calcium supplements, which was used as direct evidence for dietary intake; however, dietary interventions do not have the adverse effects of supplements. For people older than 70 years, the recommended dietary allowance for calcium is $1200 \mathrm{mg}$ daily ( 3 servings of dairy or dairy equivalents).

For residents at high risk of fractures who cannot meet the recommended dietary allowance for calcium through dietary intake, we recommend daily supplements of calcium up to $500 \mathrm{mg}$ (strong recommendation; moderate-quality evidence).

For residents who are not at high risk of fractures and who cannot meet the recommended dietary allowance for calcium through dietary intake, we suggest daily supplements of calcium up to $500 \mathrm{mg}$, depending on resources and their (or their carers') values and preferences (conditional recommendation; moderate-quality evidence).

The recommendation for residents at high risk places a high value on the reduction in hip fractures and the small reductions in vertebral and nonvertebral fractures and in mortality that can be achieved with calcium supplementation. It places a lower value on the small increased risk of gastrointestinal adverse effects that may occur and the resources required in long-term care to provide calcium supplementation.

The recommendation for residents not at high risk is conditional, as there may be little to no benefit of calcium supplementation, and adverse effects of supplementation, such as gastrointestinal and renal adverse effects, may occur. For residents who value avoiding these adverse effects, supplementation may not be a desirable option.

These recommendations apply to supplementation with any calcium compound, including calcium carbonate or citrate. The recommendation to limit supplementation to $500 \mathrm{mg}$ was based on the uncertainty about harms of calcium supplementation in studies of community-dwelling individuals who received calcium supplementation of $1000 \mathrm{mg}$ or more daily. The benefits of calcium supplementation are closely linked to adequate vitamin $\mathrm{D}$ intake.

\section{Vitamin D}

For residents at high risk of fractures, we recommend daily supplements of $800 \mathrm{IU}$ to $2000 \mathrm{IU}$ vitamin $D_{3}$ (strong recommendation; moderatequality evidence).

For residents not at high risk of fractures, we suggest daily supplements of 800 IU to 2000 IU vitamin $D_{3}$ to meet the recommended dietary allowance, depending on resources and their (or their carers') values and preferences (conditional recommendation; moderate-quality evidence).

The recommendation for residents at high risk places a high value on reductions in hip fractures, mortality and falls and a lower value on the resources in long-term care that are required to provide vitamin D supplementation. The recommendation for residents not at high risk also places a high value on reduction in falls, as they may lead to serious injuries, fear of falling and burden to staff in long-term care; however, there is some uncertainty about a reduction in falls and little to no reduction in fractures with vitamin D supplementation in this group.

These recommendations apply to supplementation with $\mathrm{D}_{3}$, as this form may be more accessible because of its lower cost relative to $D_{2}$. A dose of about $800 \mathrm{IU}$ reduced fractures in people with normal or low 25-hydroxyvitamin D levels ${ }^{24}$ and also increased 25-hydroxyvitamin D levels to normal in those with low levels, ${ }^{25}$ therefore, $800 \mathrm{IU}$ is recommended. However, the exact dose may depend on the dosing regimen that is available (e.g., a 1000 IU drop or tablet would be acceptable). The benefits of vitamin $\mathrm{D}$ supplementation are closely linked to adequate calcium intake, and therefore recommendations for calcium intake should also be applied. The recommended dietary allowance for vitamin D for people older than 70 years is $800 \mathrm{IU}$ daily, and the tolerable upper intake level is up to $4000 \mathrm{IU}$.

\section{Summary of the evidence}

Overall, there was moderate-quality evidence for benefits and low to very low quality evidence for harms of calcium and vitamin D. We found that vitamin $\mathrm{D}$ in addition to calcium probably reduces hip fractures and mortality more than vitamin D alone or calcium alone: ${ }^{24,26,27}$ for residents at high risk, we estimated 15 fewer hip fractures (95\% CI -24 to -5 ) per 1000; for residents not at high risk, we estimated 5 fewer hip fractures (95\% CI -8 to -2 ) per 1000; and for all residents, we estimated 7 fewer deaths $(95 \% \mathrm{CI}$ -14 to -1$)$ per 1000 .

\section{Box 1: Factors indicating high risk for fracture*}

Residents in long-term care with any one of the following factors:

- prior fracture of the hip or spine OR

- more than one prior fracturet OR

- recent use of systemic glucocorticoids and one prior fracturet OR

- identified as high risk and/or receiving osteoporosis treatment before admission to long-term care

*Adapted from the 2010 Osteoporosis Canada guideline. ${ }^{1}$

tExcluding fractures of the hands, feet or ankles. 
We found that vitamin D and calcium supplementation likely has little or no effect on vertebral fractures, with only 2 fewer vertebral fractures $(95 \% \mathrm{CI}-44$ to 61$)$ per 1000 . The effect is similar with vitamin $\mathrm{D}$ only, but a reduction may be likely with calcium only (49 fewer fractures [95\% CI -99 to 19] per 1000). ${ }^{26,27}$ Calcium, or vitamin $\mathrm{D}$ with or without calcium, probably has little to no effect on the incidence of nonvertebral fractures, ${ }^{24,26,27}$ quality of life ${ }^{28}$ or muscle strength. ${ }^{29}$

The data for falls were not precise (with the CIs including the possibilities of benefit, no effect and harm), and the effects were not consistent when the rate or risk of falls was measured. . $^{30-33}$ However, vitamin D and calcium, or vitamin D alone, may reduce falls. This is important because one-third of all falls may result in an injury, and every fifth injurious fall may result in treatment outside the patient's own setting. ${ }^{34} \mathrm{We}$ found no data on pain, anxiety, mobility and performance of activities of daily living in relation to calcium and vitamin D.

With respect to minor and major adverse events, vitamin D or calcium supplements probably increase mild or serious gastrointestinal events to a similar extent, by about 8 (95\% CI 0 to 17$)$ per $1000 .{ }^{26}$ Gastrointestinal symptoms or difficulties taking calcium tablets may contribute to poor adherence. ${ }^{28,33}$ The evidence suggested slightly more cases of hypercalcemia ( 5 more cases per $1000,95 \% \mathrm{CI}-1$ to 18 ) and renal insufficiency or calculi ( 3 more cases per 1000 , 95\% CI 0 to 6) with vitamin $\mathrm{D}\left(\mathrm{D}_{2}\right.$ or $\left.\mathrm{D}_{3}\right){ }^{26}$ The evidence for more myocardial infarctions with calcium supplementation of $1000 \mathrm{mg}$ or more among community-dwelling individuals is uncertain, as it is not consistent with observed reductions in mortality, ${ }^{26}$ and the CIs around the estimates include no effect and the possibility of appreciable harm..$^{35-37}$

Subgroup analyses from systematic reviews showed that there may be little or no difference in rates of fractures or falls by type of vitamin $\mathrm{D}$ $\left(D_{3}\right.$ or $\left.D_{2}\right),{ }^{26,30,38}$ that there may be greater benefits with vitamin D above 792 IU (actual intake in most studies between 792 and 844 IU) but no difference with less than or more than $1000 \mathrm{mg}$ calcium, and that there are inconsistent effects when vitamin $\mathrm{D}$ is given in large monthly or annual doses. ${ }^{24,39}$ Analyses did show that vitamin D may have greater effects in reducing falls $\mathrm{s}^{30,32}$ and fractures among people with low vitamin D status. ${ }^{24}$ Autier and colleagues ${ }^{25}$ also found that about 800 IU daily over several months can increase serum vitamin D levels to "normal" in people with initial vitamin D deficiency (e.g., $\leq 25 \mathrm{nmol} / \mathrm{L}$ ).

\section{Pharmacologic therapies for those at high risk of fracture}

When making recommendations about pharmacologic therapies for those at high risk of fracture, we placed a high value on issues that are prevalent among older persons and that may make it difficult to safely administer these medications and on the immediate risks of fractures and the consequences of falls and fractures, including increased pain, loss of mobility and greater risk of death.

We calculated the effects of benefits and harms at one year or more; as such, these recommendations apply to older persons with life expectancy greater than one year.

For residents who are at high risk of fractures, we recommend that alendronate (weekly) or risedronate (weekly or monthly) be used as firstline therapy (strong recommendation; moderatequality evidence).

The probable reductions in fractures (hip, vertebral and nonvertebral) and mortality with alendronate or risedronate outweigh the low or uncertain risk of harms or adverse effects, such as atypical femoral fractures. Alendronate and risedronate are recommended as first-line therapies because of their low cost relative to other therapies. Tablets of alendronate and risedronate are not to be crushed, and these drugs are to be provided to older persons who can remain upright for 30 minutes after administration. Some formulations must be administered at least 30 minutes before food intake. Other formulations can be taken with food.

For older persons who cannot swallow or have difficulty taking oral medications, alternative first-line therapies are available (see below for recommendations concerning denosumab and zoledronic acid). The product monographs indicate that alendronate ${ }^{40}$ and risedronate ${ }^{41}$ are not recommended for older persons with severe renal insufficiency (creatinine clearance $<35 \mathrm{~mL} / \mathrm{min}$ or $<30 \mathrm{~mL} / \mathrm{min}$, respectively).

For residents who are at high risk of fractures and who have difficulty taking oral medications, we recommend that zoledronic acid be used as firstline therapy (strong recommendation; moderatequality evidence).

The probable reductions in fractures (hip, vertebral and nonvertebral) and mortality with zoledronic acid slightly outweigh the uncertain increased risk of musculoskeletal adverse effects (e.g., arthralgia, myalgia) and the higher cost relative to other first-line therapies. This recommendation applies to older persons who have difficulty taking oral medications because of dysphagia, an inability to sit up for 30 minutes, cognitive impairment or intolerance. The product 
monograph for zoledronic acid ${ }^{42}$ indicates that infusion should be performed over no less than 15 minutes. Health Canada advises that caution is necessary for people who receive other medications that could affect renal function, that creatinine clearance should be monitored before and periodically after treatment, that appropriate hydration $(500 \mathrm{~mL}$ of water) is necessary before and after treatment, and that this medication should not be given to people with severe renal impairment (creatinine clearance $<30 \mathrm{~mL} / \mathrm{min}$ ). ${ }^{43}$

For residents who are at high risk of fractures and who have difficulty taking oral medications, we recommend that denosumab be used as firstline therapy (strong recommendation; moderatequality evidence).

The reductions in fractures (hip, vertebral and nonvertebral) and mortality with denosumab slightly outweigh the small and uncertain risk of serious infections and greater cost relative to other first-line therapies. This recommendation applies to older persons who have difficulty taking oral medications because of dysphagia, an inability to sit up for 30 minutes, cognitive impairment or intolerance. Although denosumab may be prescribed for residents with renal impairment, the product monograph for denosumab $^{44}$ indicates that in clinical studies, patients with renal impairment (creatinine clearance $<30 \mathrm{~mL} / \mathrm{min}$ ) and those receiving dialysis were at greater risk of hypocalcemia than those without renal impairment.

For residents who are at high risk of fractures, we suggest teriparatide (conditional recommendation; moderate-quality evidence).

Although the benefits of teriparatide (in particular for vertebral fractures) probably outweigh potential harms of treatment, the cost of therapy restricts access to this medication, and there may be a higher burden because of the need for daily injections. A low value was placed on the uncertain effect of teriparatide on back pain because of past and future vertebral fractures and on hip fractures.

For residents who are at high risk of fractures, we suggest that raloxifene not be used (conditional recommendation; moderate-quality evidence).

The harms of raloxifene (including venous thromboembolism and musculoskeletal events, such as arthralgia and myalgia) probably outweigh the probable reduction in vertebral fractures and the small reductions in hip and nonvertebral fractures.

For residents who are at high risk of fractures, we suggest that etidronate not be used (conditional recommendation; moderate-quality evidence).
There is moderate-quality evidence for little to no reduction in fractures (in particular, hip fractures) with etidronate. The cost of this drug is high, given the lack of important benefits.

\section{Summary of the evidence}

There is moderate-quality evidence for pharmacologic therapies from network meta-analyses of randomized controlled trials involving more than 100000 people at high risk of fractures. ${ }^{27,38,45}$ There was risk of bias in some studies and uncertainty when the effects in postmenopausal women were applied to long-term care residents. Results showed probable reductions in hip fractures of about 25 per 1000 across all drugs, but relatively smaller reductions with etidronate and raloxifene. Evidence also showed probable reductions in vertebral fractures (about 100 fewer per 1000) and nonvertebral fractures (about 20 fewer per 1000) with all drugs, but greater reductions with teriparatide and smaller reductions with raloxifene. Systematic reviews showed that reductions in mortality rates may be likely with bisphosphonates (10 fewer [95\% CI -22 to 3] per 1000), raloxifene (10 fewer [95\% CI -21 to 0] per 1000) and denosumab (23 fewer [95\% CI -46 to 6] per 1000). ${ }^{46}$ Other benefits, based on low-quality evidence, may include a small reduction in back pain related to past and future vertebral fractures for teriparatide ${ }^{47}$ but there was little to no effect on quality of life for other therapies. ${ }^{48-51}$

There was low to very low quality evidence for very small risks of serious events such as osteonecrosis of the jaw and atypical fractures or delayed healing (estimated at $<1$ per 10000 communitydwelling older people). ${ }^{52-54}$ It is unclear whether these risks would be higher among long-term care residents. The evidence for risk of atrial fibrillation with bisphosphonates ${ }^{55}$ and cerebrovascular or cardiovascular events with raloxifene was also of low quality; ${ }^{56}$ these results were imprecise and include the possibility of small to no increases in these events. Venous thromboembolism may increase with raloxifene (12 more [95\% CI 7 to 19] per 1000), ${ }^{56}$ musculoskeletal events may increase with zoledronic acid (146 more [95\% CI 125 to 169] per 1000), ${ }^{48}$ and serious infections may increase with denosumab (8 more [95\% CI 0 to 18 ] per 1000). ${ }^{57}$ Randomized controlled trials and pharmacovigilance for bisphosphonates and raloxifene showed little to no effect of these drugs on serious gastrointestinal events. ${ }^{38}$

We estimated that direct drug costs were worth the overall beneficial consequences of most drugs, with the exception of etidronate and raloxifene. The costs of zoledronic acid, denosumab and teriparatide were also high relative to those of other therapies. 


\section{Hip protectors}

For residents who are mobile and at high risk of fractures, we recommend hip protectors (strong recommendation; moderate-quality evidence).

For residents who are mobile but not at high risk of fractures, we suggest hip protectors, depending on resources available and the residents' values and preferences (conditional recommendation; moderate-quality evidence).

These recommendations place a high value on avoiding the serious consequences of hip fractures in mobile residents, including pain, loss of mobility and death. A lower value was placed on the cost or burden for an individual or for the long-term care home's resources. Given the small reductions in hip fractures achieved with hip protectors, older persons who are not at high risk may choose alternative options to prevent hip fractures. It is recognized that adherence to a recommendation to wear hip protectors may be challenging, and therefore strategies to improve adherence may be needed. This recommendation applies to hard and soft hip protectors, and the choice between them may depend on preference.

\section{Summary of the evidence}

Moderate-quality evidence from systematic reviews showed a relative risk reduction in hip fractures of $18 \%$ (95\% CI $0 \%$ to $33 \%$ ) among older persons wearing hip protectors in institutional settings. ${ }^{58}$ Over one year, four fewer hip fractures (95\% CI -7 to 0 ) per 1000 older persons wearing hip protectors may be likely, and among older persons at higher risk, 11 fewer (95\% CI -20 to 0 ) per 1000. However, one more pelvic fracture $(95 \% \mathrm{CI}$ 0 to 4) per 1000 older persons not at high risk and eight more (95\% CI -3 to 30 ) per 1000 older persons at high risk may be likely. Moderate-quality evidence also showed that there is probably little or no difference in the frequency of falls or adverse events requiring medical attention, and that minor adverse events, such as skin irritation, occurred in less than $2 \%$ of people wearing hip protectors (soft or hard). The effect on quality of life and mortality is uncertain, and data for pain, anxiety, mobility and performance of activities of daily living were not available. Adherence to hip protector use varied across studies, from $24 \%$ to $80 \%$. The impact of adherence on the effects of hip protectors is unclear, but the effects observed may represent the true effects when this strategy is implemented.

\section{Exercise}

For residents who are not at high risk of fractures, we suggest balance, strength and functional training exercises to prevent falls (conditional recommendation; moderate-quality evidence).

This recommendation places a high value on the probable small reduction in falls that is achieved with exercise, as falls may lead to serious injuries. It also places a high value on the other benefits that exercise could provide and a lower value on the uncertain costs to implement exercise interventions in long-term care settings.

For residents who are at high risk of fractures, we suggest balance, strength and functional training exercises only when such exercises are part of a multifactorial intervention to prevent falls (conditional recommendation; low-quality evidence).

This recommendation places a high value on avoiding the small increase in falls that may occur among individuals at high risk of falls who participate in exercises, such as balance, strength and functional training. Some older persons may value exercising despite the potential risk of falls. When exercise is made available to residents, it should be provided as part of a multifactorial intervention to prevent falls (including a review of medications [e.g., using the Beers criteria ${ }^{59}$ ], assessment of environmental hazards or use of assistive devices) or with other interventions to prevent fractures (including vitamin D and calcium supplementation, hip protectors and pharmacologic therapies).

\section{Summary of the evidence}

These recommendations are based on systematically reviewed evidence that is of moderate to low quality. ${ }^{31}$ This review included subgroup analyses for older persons in high-level care and intermediate-level care facilities, which were used to inform the recommendations for those at high risk and not at high risk of fractures, respectively. Most studies did not measure fractures, quality of life, mobility or pain. Instead, the risk of falls was used to inform this recommendation. Costs were not reviewed.

Subgroup analyses for high-level versus intermediate-level care among older residents at high risk of fractures suggested increases in the number of falls ( 870 more [95\% CI -210 to 2370] per 1000 older people) and the number of older persons falling ( 85 more [95\% CI -20 to 210$]$ per 1000). Among older residents not at high risk of fractures, the analyses suggested reductions in the number of falls (660 fewer [95\% CI -1290 to 390] per 1000 older persons) and the number of older persons falling ( 20 fewer [95\% CI -115 to 105] per 1000). These results were from studies that evaluated balance training (such as tai chi), strength training and functional training. One study measured hip fractures, but the results were uncertain because there were very few events. A systematic review of exercise as part of a multifactorial intervention to prevent falls showed that the multifactorial intervention might reduce falls and the number of hip fractures. ${ }^{31}$ 


\section{Multifactorial interventions}

For all residents, we suggest multifactorial interventions that are individually tailored to reduce the risk of falls and fractures (conditional recommendation; low-quality evidence).

Multifactorial interventions are defined as any combination of interventions to reduce falls that are tailored to an individual's risk. These interventions may include medication reviews (e.g., using the Beers criteria ${ }^{59}$ ), assessment of environmental hazards, use of assistive devices, exercise, management of urinary incontinence and educational interventions directed to staff. This recommendation is conditional because of the lowquality evidence for important but small benefits and the unknown and potentially greater costs to implement multifactorial interventions in longterm care. A high value was placed on the small reductions in falls that may occur, as falls may lead to serious injuries. We have not suggested which interventions should be part of a multifactorial intervention, as it is unclear which combination of strategies provides benefit. It will be important to consider the resident's level of fracture risk and tailor strategies accordingly.

\section{Summary of the evidence}

The evidence from a systematic review of interventions to prevent falls in older people in care facilities was of low quality because of the risk of bias of the included studies and the moderate to high inconsistency of effects across studies, which could not be explained by the level of care, cognition or combination of interventions. ${ }^{31}$ Most studies did not measure fractures, quality of life, mobility or pain; therefore, the risk of falls was used to inform this recommendation.

Overall, the systematic review suggested reductions in the number of falls (660 fewer falls [95\% CI -1230 to 120$]$ per 1000 older persons per year) and the number of residents who fell (55 fewer residents falling [95\% CI -115 to 10] per 1000) with the application of multifactorial interventions. There was low quality of evidence for a reduced risk of hip fractures (10 fewer [95\% CI -14 to 1] per 1000). There were insufficient data to explore the effects of different combinations of interventions, or specific interventions, and their human and financial costs.

\section{Implementation}

An overview of the implementation of these recommendations appears in Figure 1. As advocated in the American Geriatrics Society's "Guiding Principles for the Care of Older Adults with Multimorbidity, ${ }^{\circ 0}$ the preferences of residents and their caregivers must be incorporated into care. Tools that will enable organizational leaders and care teams to incorporate the recommendations into their organizational policies, structures and care processes are being developed in partnership with stakeholders (Osteoporosis Canada, www.osteoporosis.ca; Ontario Osteoporosis Strategy for Long-Term Care, www.osteoporosislongtermcare.ca). The recommendations will be reviewed as new treatment options or new evidence becomes available that changes the effects described in this guideline.

\section{Other guidelines}

These recommendations developed using the GRADE approach are consistent with recommendations for fracture prevention in residential aged care facilities in Australia ${ }^{61}$ and with the expert consensus recommendations of AMDA - The Society for Post-Acute and Long-Term Care Medicine (formerly known as the American Medical Directors Association). ${ }^{62}$ However, osteoporosis therapies available for residents at high risk of fracture vary among countries.

The optimal dosage of vitamin D supplementation for older adults has been a topic of debate within both the American Geriatrics Society ${ }^{63}$ and the US Institute of Medicine. ${ }^{64}$ Although there is agreement about evidence that a dose of $800 \mathrm{IU}$ will reduce fractures, there is less agreement about serum levels required for optimal bone health and the dosage required to achieve that level for the greatest proportion of older adults. Given the challenge of meeting vitamin $\mathrm{D}$ requirements from dietary sources and sunlight and evidence regarding the safety of vitamin D, Osteoporosis Canada has endorsed the position that individuals at high risk of vitamin D deficiency can safely take a supplement up to 2000 IU daily. ${ }^{65}$

\section{Gaps in knowledge}

These recommendations were developed after consideration of the best available evidence. In most instances, the evidence was assessed to be of moderate or low quality, and further research may therefore change the estimates of effects and our confidence in those estimates. In particular, the evidence regarding fracture reduction achieved with pharmacologic therapies was based on effects observed among 100000 postmenopausal, primarily weight-bearing women at high risk of fracture and was therefore assessed as indirect and downgraded because it may not be directly applicable to residents in long-term care. ${ }^{27,38,45}$ Further research is urgently needed to determine the efficacy and safety of osteoporosis therapies when administered to residents with limited mobility and multiple comorbidities. Future research initia- 
Fracture risk assessment on admission

- Prior hip fracture?

- Prior vertebral fracture?

- More than one prior fracture (excluding hands, feet, ankles)?

- Recent use of glucocorticoid and one prior fracture (excluding hands, feet, ankles)?

- Assessed as high risk for fracture and receiving fracture treatment before admission?

- Vertebral fracture present? (if chest radiography ordered, screen for vertebral fractures)

If "yes' to any of the above, resident is considered at high risk
Strategies to prevent fractures and falls (all residents)

Recommend:

- Dietary calcium 1200 mg/day

Suggest:

- Vitamin D ( $\geq 800-2000$ IU/day)

- Calcium supplements $\leq 500 \mathrm{mg}$, if dietary calcium not met

- Hip protectors

- Multifactorial fall-prevention strategies:

1. Exercise (balance, strength and functional training)

2. Medication reviews (e.g., Beers criteria)

3. Assessment of environmental hazards

4. Use of assistive devices

5. Management of urinary incontinence

If resident has a fracture, reassess

incontinence

\section{Recommend:}

- Dietary calcium 1200 mg/day

- Vitamin D supplements (800-2000 IU/day)

- Calcium supplements $\leq 500 \mathrm{mg}$, if dietary calcium not met

- Hip protectors for mobile residents

Suggest:

- Exercise program only as part of multifactorial fracture and fall prevention program

Recommend:

- Alendronate (70 mg weekly)

- Risedronate (35 mg weekly or 150 mg monthly)

- Denosumab (60 mg subcutaneously twice yearly)

- Zoledronic acid (5 mg IV once yearly)

Suggest:

- Teriparatide $(20 \mu \mathrm{g}$ subcutaneously daily)
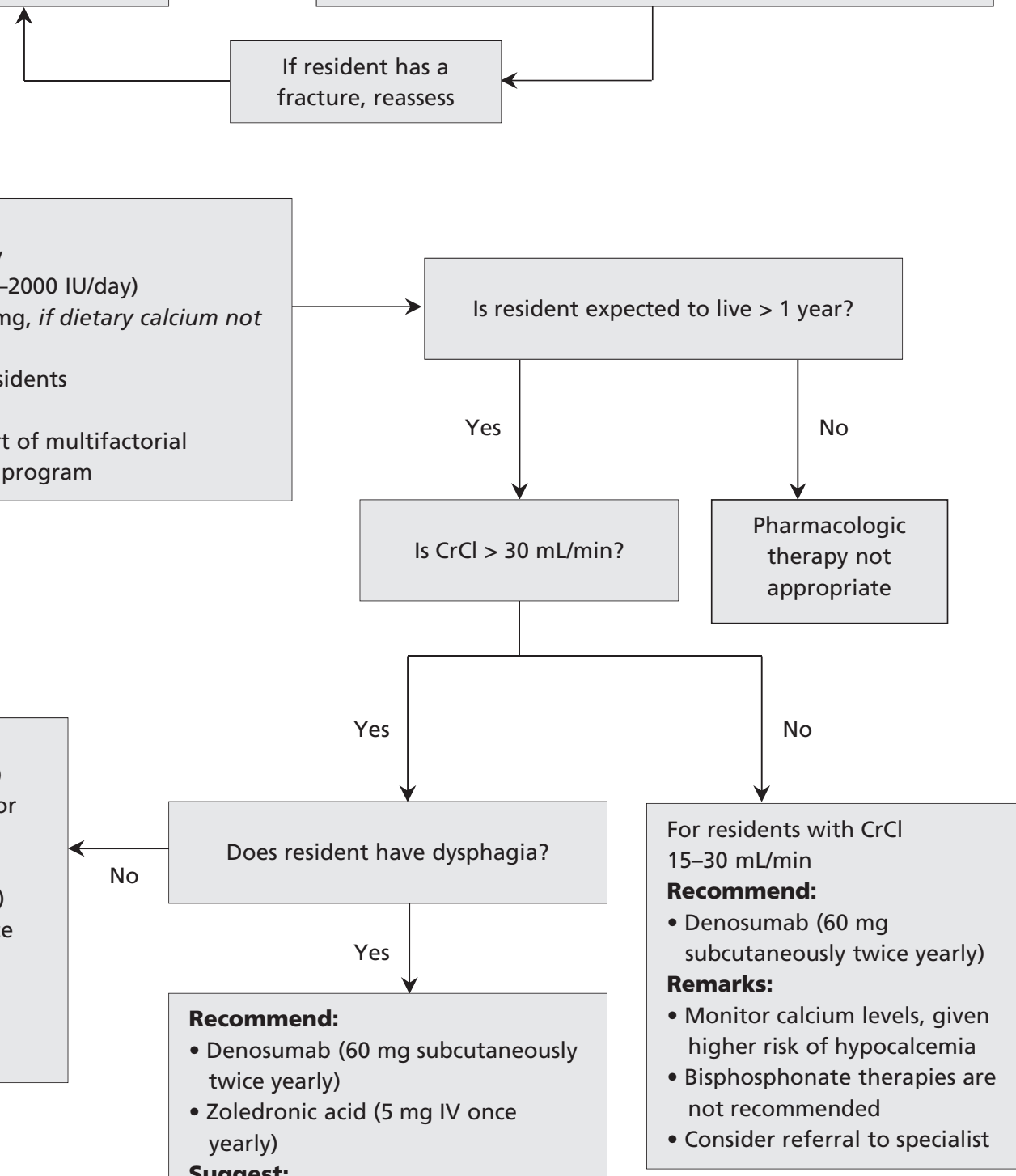

Suggest:

- Teriparatide (20 $\mathrm{\mu g}$ subcutaneously daily) 
tives should also be directed toward validating a fracture risk assessment model for long-term care; ${ }^{66-68}$ developing strategies to enhance dietary consumption of calcium; conducting studies of exercise that measure outcomes such as pain, mobility, quality of life and fractures; and innovative approaches to reduce injuries due to falls.

\section{Conclusion}

The goals of fracture prevention are to prevent pain, loss of mobility, serious injury and transfers to acute care and ultimately to maximize opportunities for quality living among long-term care residents. This guideline provides recommendations for the use of both nonpharmacologic and pharmacologic approaches to reduce fractures while considering residents' multimorbidities and life expectancy.

\section{References}

1. Papaioannou A, Morin S, Cheuxong AM, et al. 2010 clinical practice guidelines for the diagnosis and management of osteoporosis in Canada: summary. CMAJ 2010;182:1864-73.

2. Crilly RG, Tanner DA, Kloseck M, et al. Hip fractures in longterm care: Is the excess explained by the age and gender distribution of the residents? J Aging Res 2010;2010:291258.

3. Ronald LA, McGregor MJ, McGrail KM, et al. Hospitalization rates of nursing home residents and community-dwelling seniors in British Columbia. Can J Aging 2008;27:109-15.

4. Zimmerman S, Chandler JM, Hawkes W, et al. Effect of fracture on the health care use of nursing home residents. Arch Intern Med 2002;162:1502-8.

5. Nikitovic M, Wodchis WP, Krahn MD, et al. Direct health-care costs attributed to hip fractures among seniors: a matched cohort study. Osteoporos Int 2013;24:659-69.

6. Rodondi, A, Chevalley T, Rizzoli R. Prevalence of vertebral fracture on oldest old nursing home residents. Osteoporosis Int 2012;23:2601-6.

7. Papaioannou A, Watts NB, Kendler DL, et al. Diagnosis and management of vertebral fractures in elderly adults. Am J Med 2002; 113:220-8.

8. Caring for seniors with Alzheimer's disease and other forms of dementia. Ottawa: Canadian Institute of Health Information; 2010. Available: https://secure.cihi.ca/free_products/Dementia_ AIB_2010_EN.pdf (accessed 2013 May 15).

9. Easterling CS, Robbins E. Dementia and dysphagia. Geriatr Nurs 2008;29:275-85.

10. Jackson LD, Little J, Kung E, et al. Safe medication swallowing in dysphagia: a collaborative improvement project. Healthc $Q$ 2008;11(3 Spec No.):110-6.

11. Papaioannou A, Ray JG, Ferko NC, et al. Estimation of creatinine clearance in elderly persons in long-term care facilities. Am J Med 2001:111:569-73.

12. Garg AX, Papaioannou A, Ferko N, et al. Estimating the prevalence of renal insufficiency in seniors requiring long-term care. Kidney Int 2004;65:649-53.

13. Leslie WD, Berger C, Langsetmo L, et al.; Canadian Multicentre Osteoporosis Study Research Group. Construction and validation of a simplified fracture risk assessment tool for Canadian women and men: results from the CaMos and Manitoba cohorts. Osteoporos Int 2011;22:1873-83.

14. Bravo G, Dubois MF, De Wals P, et al. Relationship between regulatory status, quality of care, and three-year mortality in Canadian residential care facilities: a longitudinal study. Health Serv Res 2002;37:1181-96.

15. Reid CR. Quality of care and mortality among long-term care residents with dementia. Can Stud Popul 2008;35:49-71.

16. Cox L, Kloseck M, Crilly R, et al. Underrepresentation of individuals 80 years of age and older in chronic disease clinical practice guidelines. Can Fam Physician 2011;57:e263-9.

17. Mutasingwa DR, Ge H, Upshur RE. How applicable are clinical practice guidelines to elderly patients with comorbidities? Can Fam Physician 2011;57:e253-62.

18. Guyatt GH, Oxman AD, Vist GE, et al. GRADE: an emerging consensus on rating quality of evidence and strength of recom- mendations. BMJ 2008:336:924-6.

19. Guyatt GH, Oxman AD, Kunz R, et al.; GRADE Working Group. Going from evidence to recommendations. BMJ 2008;336:1049-51.

20. Kanis JA, Johnell O, Oden A, et al. The risk and burden of vertebral fractures in Sweden. Osteoporos Int 2004;15:20-6.

21. Chandler JM, Zimmerman SI, Girman CJ, et al. Low bone mineral density and risk of fracture in white female nursing home residents. JAMA 2000;284:972-7.

22. Leslie WD, Sadatsafavi M, Lix LM, et al. Secular decreases in fracture rates 1986-2006 for Manitoba, Canada: a populationbased analysis. Osteoporos Int 2011;22:2137-43.

23. Lindsay R, Silverman SL, Cooper C, et al. Risk of new vertebral fracture in the year following a fracture. JAMA 2001;285:320-3.

24. Bischoff-Ferrari HA, Willett WC, Orav EJ, et al. A pooled analysis of vitamin D dose requirements for fracture prevention. $N$ Engl $J$ Med 2012;367:40-9.

25. Autier P, Gandini S, Mullie P. A systematic review: influence of vitamin D supplementation on serum 25-hydroxyvitamin D concentration. J Clin Endocrinol Metab 2012;97:2606-13.

26. Avenell A, Gillespie WJ, Gillespie LD, et al. Vitamin D and vitamin D analogues for preventing fractures associated with involutional and post-menopausal osteoporosis. Cochrane Database Syst Rev 2009;(2):CD000227.

27. Murad MH, Drake MT, Mullan RJ, et al. Clinical review. Comparative effectiveness of drug treatments to prevent fragility fractures: a systematic review and network meta-analysis. J Clin Endocrinol Metab 2012;97:1871-80.

28. Grant AM, Avenell A, Campbell MK, et al.; RECORD Trial Group. Oral vitamin D3 and calcium for secondary prevention of low-trauma fractures in elderly people (Randomised Evaluation of Calcium Or vitamin D, RECORD): a randomised placebocontrolled trial. Lancet 2005;365:1621-8.

29. Muir SW, Montero-Odasso M. Effect of vitamin D supplementation on muscle strength, gait and balance in older adults: a systematic review and meta-analysis. J Am Geriatr Soc 2011;59:2291-300.

30. Murad MH, Elamin KB, Abu Elnour NO, et al. Clinical review: the effect of vitamin D on falls: a systematic review and metaanalysis. J Clin Endocrinol Metab 2011;96:2997-3006.

31. Cameron ID, Gillespie LD, Robertson MC, et al. Interventions for preventing falls in older people in care facilities and hospitals. Cochrane Database Syst Rev 2012;12:CD005465.

32. Gillespie LD, Robertson MC, Gillespie WJ, et al. Interventions for preventing falls in older people living in the community. Cochrane Database Syst Rev 2012;9:CD007146.

33. Reid IR, Mason B, Horne A, et al. Randomized controlled trial of calcium in healthy older women. Am J Med 2006;119:777-85.

34. Nurmi I, Lüthje P. Incidence and costs of falls and fall injuries among elderly in institutional care. Scand J Prim Health Care 2002;20:118-22.

35. Elamin MB, Abu Elnour NO, Elamin KB, et al. Vitamin D and cardiovascular outcomes: a systematic review and meta-analysis. J Clin Endocrinol Metab 2011;96:1931-42.

36. Bolland MJ, Avenell A, Baron JA, et al. Effect of calcium supplements on risk of myocardial infarction and cardiovascular events: meta-analysis. BMJ 2010;341:c3691.

37. Bolland MJ, Grey A, Avenell A, et al. Calcium supplements with or without vitamin D and risk of cardiovascular events: reanalysis of the Women's Health Initiative limited access dataset and meta-analysis. BMJ 2011;342:d2040.

38. Levis S, Theodore G. Summary of AHRQ's comparative effectiveness review of treatment to prevent fractures in men and women with low bone density or osteoporosis: update of the 2007 report. J Manag Care Pharm 2012;18(4 Suppl B):S1-15.

39. Bischoff-Ferrari HA, Willett WC, Wong JB, et al. Prevention of nonvertebral fractures with oral vitamin $\mathrm{D}$ and dose dependency: a meta-analysis of randomized controlled trials. Arch Intern Med 2009;169:551-61.

40. Fosamax alendronate sodium tablets [product monograph] Kirkland (QC): Merck Canada Inc.; revised 2015 Aug. 4. Available: www.merck.ca/assets/en/pdf/products/FOSAMAX-PM_E. pdf (accessed 2015 Aug. 23).

41. Actonel risedronate sodium [product monograph]. Toronto: Warner Chilcott Canada Co.; revised 2011 July 15. Available: www. sanofi.ca/products/en/actonel.pdf (accessed 2015 Aug. 23).

42. Aclasta (zoledronic acid injection) [product monograph]. Dorval (QC): Novartis Pharmaceuticals Canada Inc.; 2005 June 30, revised 2014 Sep. 11. Available: www.novartis.ca/en/products/ pharmaceuticals/index.shtml (accessed 2015 Aug. 23).

43. Updated renal safety information on Zometa (zoledronic acd) and Aclasta (zoledronic acid) - Novartis Pharmaceuticals Canada Inc. - for health professionals. Ottawa: Health Canada. Available: http://healthycanadians.gc.ca/recall-alert-rappel-avis/ hc-sc/2005/14383a-eng.php (accessed 2015 Aug. 23).

44. Prolia (denosumab) [product monograph]. Mississauga (ON): 
Amgen Canada Inc.; 2014 Oct. 20. Available: https://www. amgen.ca/Prolia_PM.pdf (accessed 2015 Aug. 23).

45. Hopkins RB, Goeree R, Pullenayegum E, et al. The relative efficacy of nine osteoporosis medications for reducing the rate of fractures in post-menopausal women. BMC Musculoskelet Disord 2011;12:209.

46. Bolland MJ, Grey AB, Gamble GD, et al. Effect of osteoporosis treatment on mortality: a meta-analysis. J Clin Endocrinol Metab 2010;95:1174-81.

47. Nevitt MC, Chen P, Dore RK, et al. Reduced risk of back pain following teriparatide treatment: a meta-analysis. Osteoporos Int 2006; 17:273-80

48. Hadji P, Ziller V, Gamerdinger D, et al. Quality of life and health status with zoledronic acid and generic alendronate - a secondary analysis of the Rapid Onset and Sustained Efficacy (ROSE) study in postmenopausal women with low bone mass. Osteoporos Int 2012;23:2043-51.

49. Sambrook PN, Silverman SL, Cauley JA, et al. Health-related quality of life and treatment of postmenopausal osteoporosis: results from the HORIZON-PFT. Bone 2011;48:1298-304

50. Jacobsen DE, Melis RJ, Verhaar HJ, et al. Raloxifene and tibolone in elderly women: a randomized, double-blind, double-dummy, placebo-controlled trial. J Am Med Dir Assoc 2012;13:e1-7.

51. Silverman S, Viswanathan HN, Yang YC, et al. Impact of clinical fractures on health-related quality of life is dependent on time of assessment since fracture: results from the FREEDOM trial. Osteoporos Int 2012;23:1361-9.

52. Rizzoli R, Burlet N, Cahall D, et al. Osteonecrosis of the jaw and bisphosphonate treatment for osteoporosis. Bone 2008;42:841-7.

53. Rizzoli R, Reginster JY, Boonen S, et al. Adverse reactions and drug-drug interactions in the management of women with postmenopausal osteoporosis. Calcif Tissue Int 2011;89:91-104.

54. Rizzoli R, Åkesson K, Bouxsein M, et al. Subtrochanteric fractures after long-term treatment with bisphosphonates: a European Society on Clinical and Economic Aspects of Osteoporosis and Osteoarthritis, and International Osteoporosis Foundation working group report. Osteoporos Int 2011;22:373-90.

55. Mak A, Cheung MW, Ho RC, et al. Bisphosphonates and atria fibrillation: Bayesian meta-analyses of randomized controlled trials and observational studies. BMC Musculoskelet Disord 2009;10:113.

56. Grady D, Cauley JA, Stock JL, et al. Effect of raloxifene on allcause mortality. Am J Med 2010;123:e1-7.

57. Toulis KA, Anastasilakis AD. Increased risk of serious infections in women with osteopenia or osteoporosis treated with denosumab. Osteoporos Int 2010;21:1963-4.

58. Santesso N, Carrasco-Labra A, Brignardello-Petersen R. Hip protectors for preventing hip fractures in older people. Cochrane Database Syst Rev 2014;3:CD001255.

59. American Geriatrics Society updated Beers criteria for potentially inappropriate medication use in older adults. New York: American Geriatrics Society; 2012. Available: http://geriatricscare online.org/ProductAbstract/american-geriatrics-society-updated -beers-criteria-for-potentially-inappropriate-medication-use-in-older -adults/CL001 (accessed 2015 Aug. 20).

60. American Geriatrics Society Expert Panel on the Care of Olde Adults with Multimorbidity. Guiding principles for the care of older adults with multimorbidity: an approach for clinicians. $J$ Am Geriatr Soc 2012;60:E1-25

61. Duque G, Close JJ, deJager JP, et al. Treatment for osteoporosis in Australian residential age care facilities. Med J Aust 2010;193:173-9.

62. Osteoporosis and fracture prevention in the long-term care setting: clinical practice guideline. Columbia (MD): American Medical Directors Association; 2009.

63. American Geriatrics Society Workgroup on Vitamin D. Supplementation for older adults. Recommendations abstracted from the American Geriatrics Society consensus statement on vitamin D for prevention of falls and their consequences. J Am Geriatr Soc 2014;62:147-52.

64. Rosen CJ, Abrams SA, Aloia JF, et al. IOM committee members respond to Endocrine Society vitamin D guideline. J Clin Endocrinol Metab 2012;97:1146-52.

65. Hanley DA, Cranney A, Jones G, et al. Vitamin D in adult health and disease: a review and guideline statement from Osteoporosis Canada. CMAJ 2010;182:E610-8

66. Girman CJ, Chandler JM, Zimmerman SI, et al. Prediction of fracture in nursing home residents. J Am Geriatr Soc 2002;50:1341-7.

67. Colón-Emeric CS, Biggs DP, Schenck AP, et al. Risk factors for hip fracture in skilled nursing facilities: Who should be evaluated? Osteoporos Int 2003;14:484-9.

68. Chen JS, Sambrook PN, Simpson JM, et al. A selection strategy was developed for fracture reduction programs in frail olde people. J Clin Epidemiol 2010;63:679-85.

Competing interests: Alexandra Papaioannou has received grants and research support from Amgen, Eli Lilly, Merck and Warner Chilcott and speaker's honoraria from Amgen, Eli Lilly and Merck. Suzanne Morin has received research grants from Amgen and Merck and consulting fees from Amgen and Eli Lilly. Jonathan Adachi has participated in clinical trials for Amgen, Eli Lilly, Merck and Novartis, and has received consulting fees and speaker's honoraria from Amgen, Eli Lilly, Merck, Novartis and Warner Chilcott. Richard Crilly is on the national advisory board for Amgen.Lora Giangregorio has received grants and research support from Merck. Robert Josse has been an advisory board member and has received speaker's honoraria and/or research grants from Lilly, Amgen and Merck. Hope Weiler has received funding from the Dairy Farmers of Canada. Susan Whiting is an education consultant for Yoplait France and Pfizer Consumer Healthcare, and has received research funding from the Dairy Farmers of Canada and the Saskatchewan Health Research Foundation. Angela Cheung has received grants and honoraria from Amgen, Eli Lilly and Merck. Alexandra Papaioannou, Suzanne Morin, Sidney Feldman, Robert Josse and Angela Cheung are members of the Guideline Committee for the Scientific Advisory Board of Osteoporosis Canada. No other competing interests were declared.

Affiliations: Department of Medicine (Papaioannou, Adachi, Pickard), Department of Clinical Epidemiology and Biostatistics (Papaioannou, Santesso) and School of Nursing (Kaasalainen), Faculty of Health Sciences, McMaster University, Hamilton, Ont.; Geriatric Education and Research in Aging Sciences Centre (Papaioannou, Pickard, Skidmore), St. Peter's Hospital, Hamilton, Ont.; Department of Medicine (Morin), McGill University Health Centre, Montréal, Que.; Montreal General Hospital (Morin), Montréal, Que.; Department of Medicine (Feldman, Josse, Moser, Cheung) and Department of Physical Therapy (Jaglal), University of Toronto, Toronto, Ont.; Baycrest Geriatric Health Care System (Feldman, Katz, Moser), Toronto, Ont.; St. Joseph's Healthcare (Adachi), Hamilton, Ont.; Division of Geriatric Medicine, Department of Medicine (Crilly), University of Western Ontario, London, Ont.; Department of Kinesiology (Giangregorio), University of Waterloo, Waterloo, Ont.; Institute for Clinical Evaluative Sciences (Jaglal), Toronto, Ont.; Li Ka Shing Knowledge Institute (Josse), St Michael's Hospital, Toronto, Ont.; School of Dietetics and Human Nutrition (Weiler), McGill University, Montréal. Que.; Department of Nutrition and Dietetics (Whiting), University of Saskatchewan, Saskatoon, Sask.; Toronto General Hospital (Cheung), Toronto, Ont.

Contributors: Alexandra Papaioannou and Nancy Santesso led the research group responsible for reviewing and synthesizing the evidence, developing the recommendations and drafting the manuscript. Nancy Santesso oversaw the application of the GRADE approach to guideline development and facilitated the guideline panel. All authors contributed to the discussion of issues related to care of older people and/or osteoporosis care, exercise and nutrition. All authors reviewed the final recommendations, and all reviewed and approved the final manuscript and agree to act as guarantors of the work

Funding: This initiative was supported by the Ontario Osteoporosis Strategy for Long-Term Care, which is funded by the Ontario Ministry of Health and Long-Term Care and Osteoporosis Canada. Support from the Canadian Institutes of Health Research (MAG - 119120) allowed many longterm care stakeholders to participate in the guideline panel and to meet face to face. Unrestricted educational grants were provided by Amgen Inc., Eli Lilly Canada Inc., Merck Canada Inc. and Warner Chilcott.

Acknowledgements: The authors are grateful for the participation and support of many stakeholders from the long-term care and osteoporosis communities: Mary-Lou van der Horst, Dr. Amy Maher, Dr. Christopher Frank, Dr. Angela Juby, Dr. Sharon Marr, Dr. Manuel Montero-Odasso, Dr. Denis O’Donnell, Dr. Patrick Quail, Dr. Diane Villani, Carol Holmes, Linda Dacres, Dee Lender, Milly Radford, Paula Neves, Kathryn Pilkington, Samantha Peck, Ina Ilse, Kerry Grady, Ravi Jain, Lisa Campbell, Monica Menecola, Dr. George Ioannidis, Dr. Courtney Kennedy, Dr. Janet Pritchard, Keya Shah, Osman Osman and Dr. Robert Hopkins. 